University of California, Hastings College of the Law UC Hastings Scholarship Repository

Faculty Scholarship

1993

\title{
LongTerm Strategies in Japanese Environmental Litigation
}

Setsuo Miyazawa

UC Hastings College of the Law, miyazawa@uchastings.edu

Follow this and additional works at: http://repository.uchastings.edu/faculty_scholarship

Part of the Environmental Law Commons, and the Litigation Commons

\section{Recommended Citation}

Setsuo Miyazawa, LongTerm Strategies in Japanese Environmental Litigation, 18 Law \& Soc. Inquiry 605 (1993).

Available at: http://repository.uchastings.edu/faculty_scholarship/1216

This Article is brought to you for free and open access by UC Hastings Scholarship Repository. It has been accepted for inclusion in Faculty Scholarship by an authorized administrator of UC Hastings Scholarship Repository. For more information, please contact marcusc@uchastings.edu. 


\section{Long-Term Strategies in Japanese Environmental Litigation}

\section{Robert L. Kidder and Setsuo Miyazawa}

Japan's reputation for unusually strong emphasis on the avoidance of public conflict and therefore for deemphasis of legal institutions suggests an arid, hostile environment for litigators, especially those who lack substantial resources. In a study of a quasi-class action lawsuit by Japanese air pollution victims, we find that litigation can be developed as a tool in the pursuit of a social movement's wider objectives despite the paucity of resources within the Japanese legal system. Our research documents the many ways in which the delays, obstacles, and costs that characterize the litigation environment in Japan have been either neutralized or turned to the advantage of a social movement because of its commitment to longer-term political objectives rather than short-term victories. The special role of professions in general and the legal profession in particular, in such litigation combines with class-oriented social movements to produce a political/legal pattern that is neither traditionally harmonious nor a conflict "difficult to contain."

When a large group of Japanese air pollution "victims" files suit against the national government and major industrial organizations, how did they reach that decision, what do they want, what conditions will affect their court outcomes, and what effect will the law-centered experience have on their lives as individuals and as members of a social movement? We address these basic questions in this study. We will also consider their implications for broader issues of law in society generally and law in Japan specifically. Because our approach is comparative, and because the Japanese legal context of this lawsuit is important in producing the answers to our questions, we begin with a review of the context which an American group with similar pollution problems might face.

Robert L. Kidder is a professor in the Department of Sociology at Temple University. Setsuo Miyazawa is on the Faculty of Law of Kobe University. 
Environmental social movements in the United States are often subsets of broader movements for social change. Typically these movements include litigation as one means of furthering their goals. Some defendants are private parties whose actions have caused, or threaten, dangers or destruction. In other cases, government agencies are sued for failure to enforce regulations, or as a means of pressuring those agencies to carry out their responsibilities more assertively.

Environmental activism in the U.S. has tended to coalesce into nationwide organizations such as the Sierra Club, Greenpeace, and the Wildlife Fund. These mass-membership organizations raise significant resources to support high-impact litigation. By high-impact litigation, we mean lawsuits in which the object is to obtain judgments, written opinions, and the attendant publicity from actions of the highest federal courts in order to set precedents (what Galanter has called "rule development" and the pursuit of "rapid and elaborate development of the doctrinal law")" that will alter the behavior of polluters all over the country. In other words, in addition to pressing legislatures to write environment-friendly laws, antipollution organizations regularly use the courts to produce social change through court-centered precedent. ${ }^{2}$

Community groups who wish to attack a specific local environmental problem can seek one or more of these nationwide organizations to act as a champion. The organizations respond selectively, taking on those "clients" with "significant" cases-those in which successful litigation will produce both good publicity and valuable new precedent.

With numerous environmental-protection laws already passed by both the federal and state levels, local activists are well armed with a generally favorable legal climate for action. This remains true even in the face of a fluctuating political and administrative environment. Nevertheless, as previous research has repeatedly shown, laws are not self-enforcing and regulatory laws in particular depend on factors such as the limited resources allocated to regulators, the political inclinations of the administration for which they work, and the changing structures and mechanisms of control. ${ }^{3}$ Hence the majority of environmental actions in recent years has

1. Marc Galanter, "Why the 'Haves' Come out Ahead: Speculations on the Limits of Legal Change," 9 Law \& Soc'y Rev. 112 (1974).

2. According to Percy Luney, a board member of the Environmental Defense Fund, many environmental groups in the United States now prefer negotiations over litigation. The National Environmental Policy Act allows such organizations to participate in regula. tory procedures.

3. See S. Cohen, "The Punitive City: Notes on the Dispersal of Social Control," 3 Contemp. Crisis 339 (1979); Richard L. Abel, "The Contradictions of Informal Justice" in Abel, ed., The Politics of Informal Justice (New York: Academic Press, 1982) ("Abel, Politics"); Boaventura de Souza Santos, "Law and Community: The Changing Nature of State Power in Late Capitalism," in Abel, Politics; Pat O'Malley, "Regulating Contradictions: The Australian Press Council and the 'Dispersal of Social Control,' " 21 Law E Soc'y Rev. 83 (1987); Jonathan Simon, "The Ideological Effects of Actuarial Practices," 22 Law \& Soc'y Rev. 771 
been centered on using litigation to enforce existing laws. An example is the use of regulations requiring "environmental impact studies" to be performed before new development projects can be started. Courts have become the center of battles over the protection of one or another "endangered species" such as the Snail Darter fish in Tennessee or the Northern Spotted Owl in the Northwest where the cutting of forests is being contested.

In the United States, therefore, localized pollution initiatives arise and exist within a nationwide ecology of mobilized resources including networks of supporters and activists who use litigation at various levels as part of their strategy for environmental protection. Their actions are supported not only by thousands of voluntary donors, both individual and corporate, who support environmentalism in general, but also by the large number of activist lawyers who are available to work full time on environment-related issues. For U.S. activists, there is an abundance of legal resources, and these resources have become incorporated into the long-term strategies of environmental activism.

In this article, we will use a case study to compare this American pattern with research results on antipollution activism and litigation in Japan. Among social scientists, Japan is known for two factors that are relevant to this research: its unfortunate position as a pioneer in pollution experience in the Minamata disease cases; ${ }^{4}$ and its reputation as a society with a culturally based aversion to dependence on the law and courts. Our research focuses on the relationship between Japan's scarce legal resources and the strategies of social mobilization used by environmental activists.

For decades, social scientists have tended to rely on culture as an independent variable explaining all sorts of differences between Japan and other industrialized societies. Japan's low rates of litigation and the "underdevelopment" of its legal institutions have been no exception. Kawashima's discussion of the legal system is one of the best-known English-language treatments of culture-based analyses. ${ }^{5}$ In brief, the culturebased hypothesis is that the traditional Japanese esteem for harmony and institutions expressing that value system have made legal institutions and procedures aesthetically unpalatable and functionally unnecessary. Culture, they argue, supports functional alternatives to legal structures that

(1988); Julie Horney \& Cassia Spohn, "Rape Law Reform and Instrumental Change in Six Urban Jurisdictions," 25 Law \& Soc'y Rev. 117 (1991); lan Ayers \& John Braithwaite, "Tripartism: Regulatory Capture and Empowerment," 16 Law \& Soc. Inquiry 435 (1991).

4. See Frank Upham, Law and Social Change in Post-War Japan (Cambridge, Mass.: Harvard University Press, 1987) ("Upham, Law in Post-War Japan"); for a complete chronology of Japan's history of pollution problems and related social actions, see Nobuko Iijima, ed., Pollution Japan: Historical Chronology (Tokyo: Asahi Evening News, 1979).

5. Takeyoshi Kawashima, "Dispure Resolution in Contemporary Japan," in A. T. von Mehren, ed., Law in Japan: The Legal Order of a Changing Society (Cambridge, Mass.: Harvard University Press, 1963) ("Kawashima, 'Dispute Resolution" "). 
have developed in the West. More recent versions of this thesis deal with apology ${ }^{6}$ and with the social psychology of justice. ${ }^{7}$

Other research on connections between law and society in Japan has challenged these culture-based explanations for Japan's legal "underdevelopment" and the relative infrequency of Japanese litigation. One type of challenge emphasizes relationships between different elements of Japan's elite, the emphasis of postwar Japanese leaders on rapid economic expansion, and conditions affecting the success of interest groups in transforming their local problems into issues of broader import. ${ }^{8}$ This approach depicts the Japanese love of harmony as a useful myth by which a power elite justifies deliberate suppression of growth of legal institutions. Other studies make a similar point by demonstrating the economic rationality of Japanese decision making about whether or not to litigate, given institutional contexts, including the high costs of lawyers and litigation, which make settlement strategies measurably less expensive than litigation. ${ }^{9}$ In both of these versions, the law-averse behavior of ordinary Japanese citizens becomes "rational" because it reflects decisions that make sense from a self-interested viewpoint within the confines of the socioeconomic structures that determine opportunities in Japan.

Regardless of theory, most observers agree that Japan stands out as a rare exception to the trend toward legalization in industrial and postindustrial societies. Social movements addressing environmental issues face a very different legal landscape from that which most Americans have come to take for granted. If America is a legal jungle, Japan is a desert. The story we tell here represents a "negative case"-a group of people who are using the legal system, who are confronting their opponents in court, who, in other words, are apparently not obeying the unwritten rules of Japanese culture. In our report, we will show how people in Japanese social movements adjust to and use the scarce legal resources and the opportunities

6. Hiroshi Wagatsuma \& Arthur Rosett, "The Implications of Apology: Law and Culture in Japan and the United States," 20 Law E Soc'y Rev. 461 (1986).

7. V. Lee Hamilton \& Joseph Sanders, Everyday Justice: Responsibility and the Individual in Japan and the United States (New Haven, Conn.: Yale University Press, 1992) ("Hamilton \& Sanders, Everyday Justice"). In their book, Hamilton and Sanders go well beyond the references earlier in linking cultural factors to those of social structure. Still, their analysis tends to treat the attitude differences they find as an important causal factor in retarding the development of legal institutions in Japan.

8. Margaret McKean, Environmental Protest and Citizen Politics in Japan (Berkeley: University of California Press, 1981); Upham, Law in Post-War Japan; Setsuo Miyazawa, "Social Movements and Contemporary Rights in Japan: Relative Success Factors in the Field of Environmental Law," 22 Kobe U. L. Rev. 63 (1988); John O. Haley, "The Myth of the Reluctant Litigant," 4 J. Japanese Stud. 359 (1978).

9. Takao Tanase, "The Management of Disputes: Automobile Accident Compensation in Japan," 24 Law \& Soc'y Rev. 651 (1990); J. Mark Ramseyer \& Minoru Nakazato, "The Rational Litigant: Settlement Amounts and Verdict Rates in Japan," 18 J. Legal Stud. 263 (1989). 
found at the oases of this "legal desert." We will also address the changes that litigation may produce in social movements which do go to court.

In the late 1980s 482 residents of Kojoshi [pseudonym], an industrial suburb of a major Japanese metropolitan center, filed a multibillion yen lawsuit against nine local companies, the national government of Japan, and a public highway corporation. In addition to damages (various lung diseases) stemming from air pollution, they demanded injunctive orders to keep below specific levels sulfur dioxide from the defendant companies and nitrogen dioxide from the highway passing through their area. ${ }^{10}$ Their indirect purpose in demanding these orders is to force the government to reinstate a previously established compensation system that the national government had used to deal with the pollution crisis of the late 1960s. How did this citizen action come about? How is it organized? What does it tell us about "access to justice" in the Japanese legal system and the relationship between Japanese legal institutions and social movements? The general objective of the research we report here has been to situate this lawsuit sociologically in the formation and evolution of the particular social movement from which it has sprung. To the extent that it may be more than just an idiosyncratic case, it may tell us something more general about law and social movements in Japan. In the process, the research may also provide some answers for broader questions about law and social movements in general. With respect to the debate over culture versus other explanatory schemes, we will try to show the inadequacy of a reliance on culture to explain this case.

\section{LITIGATION AND SOCLAL MOVEMENTS}

Until Japan began planned industrial development, Kojoshi was a quiet fishing village. Everything changed when national government chose the whole region as a new heavy industry development zone. Like its neighboring towns in both directions along the seacoast, Kojoshi was quickly transformed into a sprawling center for smokestack industries such as steel, glass, and power generation. By the 1930s it was a predominantly industrial area in which pollution of various kinds was probably already producing health problems.

Kojoshi is now a city of about 600,000 people. It is divided between a relatively affluent section "across the tracks" and outside the prevailing drift of the city's oceanside regiments of smokestacks, and the other half that routinely receives the pollutants issuing from those stacks. This "other half" is a relentlessly industrial area, with a few very large factories

10. For a more detailed description of the legal issues involved in this case, see the appendix. 
and hundreds of much smaller ones scattered in among the working-class neighborhoods. The area merges indistinguishably with similar industrial strips on either side of it.

Air pollution in Kojoshi has led a large group of residents to conclude that litigation is rational, that the group needs to confront both private industry and government with public legal action. These lawsuits therefore represent the nonharmonious option which is not consistent with the Japanese ideology of consensus, the culture of $\mathrm{Wa}$. Is this action an aberration, just a peculiar local outburst? Or does it contain elements that tell us something new about the relationship between "the people" and the Japanese legal system, about factors that Japan shares with other industrialized legal systems, and therefore about more global patterns of response to environmental problems through legal activity? In particular, how do the structural restrictions on development of law in Japan affect the strategies these plaintiffs use to achieve their goals?

\section{METHODS}

The research reported here is largely based on interviews conducted by the authors with those involved in this litigation on the side of the plaintiffs. We have interviewed those lawyers who are involved as "active" advocates in the preparation and presentation of the case, leaders of the plaintiffs' organization and leaders of the more inclusive victims' organization from which the plaintiffs were drawn, and an opportunistically drawn (not random) sample of plaintiffs. We have accompanied lawyers during their interviews of plaintiffs in their homes and conducted our own interviews of those and other plaintiffs. We have also interviewed two doctors and a high school science teacher who originally helped define Kojoshi's problem as a case of air pollution and the doctor who has treated more than half of the plaintiffs.

In addition to interviews, we have studied the publicity material distributed by the victims' organization and the plaintiffs' organization, and the stories about their actions and the progress of the litigation which have appeared in both Japanese and English language papers and on television.

\section{THE KOJOSHI CASE}

The Kojoshi litigants are a subset of "certified victims" of sulfur dioxide pollution in Kojoshi. Victims obtained their "certified" status beginning in 1970 through a coincidence of their own efforts and major changes in the policies of the national government. The origins of "victim con- 
sciousness" and certification include both local action and external influence. Beginning in the late 1960 s, various Kojoshi residents became concerned about the high incidence of respiratory disease, especially among Kojoshi's children. Emphysema, bronchitis, and asthma were all higher than local doctors thought normal. These doctors communicated their concern to parents and began helping a few of them to investigate causes. To do this, they felt they needed to measure the extent of the problem, and this required contacting other parents. With the help of local science teachers who sought the source of the problem with crude experiments, and local doctors who helped organizers track the geographic pattern of disease, they identified the problem as air pollution and traced it to local factories. The epidemiological phase thus involved actions which, in retrospect, were well-suited to the formation of a social movement.

The timing here is important because it is simultaneous with the climax of the "Big Four" pollution cases (Minamata, Yokkaichi, Niigata, and Toyama)," which had captured the nation's (and eventually the world's) attention and prodded the national government into dramatic antipollution action. Thus, just as the "big" cases were pressing the national government to enact enlightened new environmental standards, groups of Kojoshi citizens were putting together their own homemade version of a pollution case.

The specific channel by which the idea of air pollution entered this local scene appears to be through a local doctor who innocently welcomed a group of medical students on a study tour from Tokyo. In his own words, before the arrival of the students, he had always considered Kojoshi's smokestacks and soot to be "a symbol of progress and achievement. .., an object of pride for the community." But the students arrived with a letter from their professor questioning the doctor about diseases in his town that might be related to air pollution. He relates that this was the first time he ever considered the possibility that the air might be dangerous. Yet it was from this seed of doubt that the doctor began his own investigations and began to communicate his doubts to his patients, some of whom became the nucleus of the new movement.

This growing group of local residents persuaded the city government to institute a system for the compensation of air pollution victims. The municipal program began operation in 1970, just prior to the introduction of a nationwide compensation program for pollution zones "designated" by the national government. The national program involved a tax on industrial polluters which was used to create a compensatory fund for "certified" pollution victims in many industrial towns including Kojoshi. Its

11. See Upham, Law in Post-War Japan, and McKean, Environmental Protest and Citizen Politics in Japan. 
purpose was not to punish polluters, nor even to force an end to pollution, but rather to help those who suffered its effects. Since the pollution tax was calibrated to the level of pollution output, the program was expected to gradually reduce pollution in response to economic incentives. However, the primary thrust of the program was support for those who suffered from the pollution. To become "certified" as a victim, one had to prove residence in a designated polluted area for at least a year and present symptoms of one of four classes of respiratory disease (emphysema, asthma, asthmatic bronchitis, and bronchial asthma). Kojoshi was included in the first group of "designated areas."

A special characteristic of this program is that "victims" need not demonstrate a direct causal relationship between any one polluter and their own contraction of disease. Nor do "victims" have to prove a causal link between the pollutants and their disease. Liability of polluters is collective and causality is assumed. The primary agent of pollution-caused disease has been identified as sulfur dioxide.

Currently, nearly 11,000 Kojoshi residents are certified as "victims," with level of disease severity determining the level of compensation they receive from the fund. Simultaneous with their efforts to gain certification, a majority of the victims formed into civic associations using volunteer help and contributions from the city to develop a social service network for victims and their families. By the time we began interviewing in the spring of 1989 , the organization involved in the litigation was operating 16 neighborhood-based offices scattered about the city to bring services for victims and their families close to home. ${ }^{12}$

Beginning with legislative moves in 1980 , the national government has been moving to curtail its compensation program, starting with legislation to narrow the range of eligibility for victim certification and reduce the financial burden placed on the polluting industries. The pace and scope of this reduction grew more intense in 1983, and the victims' association began looking for ways, including political action and litigation, to ensure the continuation of the program. In 1987, however, government support was cut sharply. The Pollution Health Damage Compensation Act was amended, terminating certification of new victims. In effect, the ruling party and relevant agencies have declared sulfur dioxide pollution a thing of the past. ${ }^{13}$ The policy change clearly came in response to pressure from

12. Many victims literally cannot walk a couple of blocks to shop at their neighborhood stores. The exertion leaves them breathless. Hence, many depend on the social service network of the victims' association to allow them to continue living at home.

13. Sulfur dioxide pollution has been significantly reduced throughour Japan, though not eliminated entirely. Kojoshi victim leaders and their lawyers confess in private that they know sulfur dioxide is no longer such a problem, but they continue to press the issue for two reasons: first, to keep up pressure on the government to care well for those who have already fallen prey to sulfur dioxide; and, second, to strengthen their hand in dealing with the more significant contemporary pollution threat from nitrogen dioxide emissions from 
industrial leaders to eliminate the competitive disadvantages of regulatory burdens on industry. To make this pill more palatable to the general public, government simultaneously created a fund for research and other preventive measures using contributions from industries. Besides the victims themselves, many local governments opposed this amendment.

The Kojoshi victims' lawsuit, filed in December 1988, was mostly a response to this policy change. It demands injunctive orders to reduce air pollution caused by sulfur dioxide and nitrogen dioxide to specific maximum levels. Further, it demands nearly 12 billion yen (about $\$ 92$ million) in damages to the victims. The suit is intended to place indirect pressure on the government to reinstate the compensation system by legally confirming the existence of a large number of uncompensated victims. While the repealed compensation system did not deal with nitrogen dioxide emitted from cars traveling on a highway built 15 years ago, the suit demands an injunctive order on nitrogen dioxide as well because the highway system is now the more significant polluter of Kojoshi.

A "team" of 218 lawyers was formed. Forty of these are "active" in the case, and the rest have consented to be listed as a show of support for the case. Seven to 10 of them work on the lawsuit more or less full time. Most of these active lawyers work in law firms that are of medium size by Japanese standards (6-12 members), and it is quite clear that their largely uncompensated work on these cases is being subsidized by the other, more lucrative work being done in these firms.

The litigants' organization has evolved into a quite sophisticated social movement. It prints and distributes glossy brochures (some in both Japanese and English) detailing their case for continued support, it produces a publicity campaign involving public speeches and articles for newspaper and television coverage, and it operates a permanent litigation office near the district court where the lawsuit is being heard, with a staff that works on the litigation full time, stores records, and maintains computer contact with legal directories. Lawyers' fees have been minimal thus far, and lawyers we have interviewed expect most of their work to be uncompensated. Support for the lawyers and for the organization's litigation office is produced by a monthly "membership" fee charged each litigant.

Both lawyers and victims agree that final judgments in the courts are not likely to come earlier than around 1998 , at least 10 years after initial filing of the case. In the 3 years since the case was filed, more than 20 of the litigants have died. ${ }^{14}$

automobiles. Automobile pollution has risen sharply in most urban areas and constitutes a special threat in Kojoshi because of the 16-lane expressway built through the heart of the area.

14. This figure has been revised upward every time we have conducted interviews for this project. 


\section{LITIGATION IN CONTEXT: ACTION NETWORKS}

The facts outlined above are the bare bones of the case history. We have told it as though litigation were the logical culmination of events. It is the kind of description one might have seen some years ago in an article on "access to justice," with the emphasis on the severe handicaps faced by these victims because of inadequacies in the Japanese legal system. As described, with the delays involved, it also might be taken as additional evidence in support of Hamilton and Sanders's psychocultural argument that "[l]ack of [legal] alternatives-essentially lack of a 'court of last resort'can contribute to endless controversy" in cultures that, like that of Japan, "do not look to the courts for an acceptable resolution to conflict." 15

Our research, however, leads us to view both of these approaches as inadequate for understanding this situation. In the face of restricted "access to justice," a determined social movement can turn barriers into a positive element of strategy for precisely those who "suffer" most from "deficient" legal resources. The scarcity of legal resources does not necessarily stifle grass-roots social movements in their efforts to pursue justice and social change, though the scarcity may significantly restrict opportunities for the individuals who make up the movement. Instead, the scarcity of legal resources can be factored into a social movement's calculations and become a source for its revitalization as well as the basis for maintenance of control over the movement's direction. Rather than exemplifying what Hamilton and Sanders see as a general "difficulty of containment" of conflict, ${ }^{16}$ we believe the continuing chain of events in these pollution cases represents a quite highly scripted pattern of conflict that only appears to be "uncontained" because its unfolding is not significantly governed by decisive judicial action. Nor should the duration of this activity be taken as evidence of the kind of structureless floundering that is implied in Hamilton and Sanders's expression, "endless controversy." 17 The controversy may be long-lived, but a better label for it would be "sustained opposition."

Our interviews show that participants in the formation of the victims' organization in Kojoshi already had, or later developed, contacts with people in other areas where pollution was becoming an issue. We know also that they were aware of some details of the "Big Four" pollution lawsuits. Some of the leadership of Kojoshi's victims' organization participated in

15. Hamilton \& Sanders, Everyday Justice 215 (cited in note 7), argue that social systems lacking in legal resources may be "fragile" because they lack the means to absorb conflict through means other than reliance on norms of harmony. Hence, they say, when conflict does break out in a "harmonious" culture, it is likely to be difficult to contain, to be unnecessarily protracted, and to involve unpredictable battles.

16. Id. at 214.

17. Id. at 215. 
the "study groups" of victims' organizations in neighboring cities which were preparing lawsuits similar to the one eventually filed by Kojoshi victims. This helps to explain the substantial similarity between the definitions of the problem and the actions taken between Kojoshi and other areas where air pollution activism was emerging, including the "big" one in Yokkaichi. While there are few if any nationwide organizations in Japan that compare with the mass movements in other industrialized settings such as the United States or the European Community, smaller, less conspicuous nationwide networks do exist in Japan.

These similarities in the use of litigation did not occur by chance. Kojoshi victims' leaders have kept themselves well informed about the often convoluted developments and outcomes of other contemporary lawsuits that are quite similar to their own, and have been in regular contact with leaders in these other communities. We can directly trace this contact at least back to the period (the early 1970s) when Kojoshi's organization was being formed. Kojoshi victims played a part in establishing the Japan Air Pollution Victims' Association, a national organization that began as a "liaison group" (renrakukai) with other victims' groups in 1973 and became a policy-promoting federation eight years later.

In a very recent development, an almost identical lawsuit filed by victims in Kita-tonari [pseudonym], a "clone" of Kojoshi that was being polluted by Kojoshi's factories but that was located in a separate judicial jurisdiction, was adjudicated partially in favor ${ }^{18}$ of the plaintiffs. Filed in 1978 and reaching original-trial adjudication in early 1991, the suit by about 120 victims resulted in a total award of nearly 400 million yen ( $\$ 3$ million) from the private industries involved, but it failed to hold government liable and it failed to impose any controls on auto emissions. Significantly for our research on the social movement aspects of this litigation, about 6,000 demonstrators were present at the district court on the day the decision was announced, including scores of members from the Kojoshi victims' organization. They joined the Kita-tonari victims in demonstrations outside the court before the final hearing and went with them immediately after the "victory" in separate teams to the various corporate headquarters of the defendant companies to confront their managements with the demand to avoid further litigation, curtail further pollution, and apologize to the victims.

Political parties opposed to the ruling Liberal Democratic party have had an interest in these issues and have had some degree of contact with

18. Like most decisions in these cases, the judgment cannot be easily categorized as a "victory" or a "defeat" for either side. The amount of the settlement is enough to make individual participants feel that such cases are worth the effort, but there is also disappointment about the failure to achieve some of the larger goals. The more highly committed movement participants scan such decisions not for their immediate payoff but for their potential for opportunity or threat in pending or future lawsuits in other jurisdictions. 
the victims' organization. In public, the Kojoshi plaintiffs' organization has worked hard to maintain a nonpartisan stance. For example, among the many lawyers assisting them, either in name or in practice, in their lawsuit, the full political spectrum is represented, and active leaders of both the lawyers' group and the plaintiffs' association say that wide representation was a specific goal in putting together the lawyers' team. Nevertheless, the lawyer originally serving as head of the lawyers' team is associated with the Japan Communist Party, and several of the lawyers involved in this lawsuit have been active in a variety of other lawsuits involving liberal or "left" issues such as civil rights for prisoners, illegal immigrants, disabled students, and resident Koreans, and issues involving the rights of labor unions. Resident Koreans are Japan's largest minority group and have figured prominently in recent years in conspicuous demonstrations for fair treatment. Some Kojoshi litigants are resident Koreans, but most are native Japanese. While it is a distortion to say that the victims' movement is a tool of one or more political parties, it is fair to say that the broader network supporting this litigation intersects with both the ideologies and organizations of opposition politics.

\section{THE PROBLEM OF ACCESS}

Our interviews show that organization leaders approached lawyers as early as 1972 concerning their desire to sue the polluters. Their experience with local lawyers was almost entirely negative. They did manage to engage one activist lawyer in the cause. But while "studying" the potential for a suit, this lawyer became involved in another suit to enjoin the construction of the very highway which has since become one target in the current Kojoshi antipollution suit. That lawyer "drifted away" into the highway case because, according to victim leaders, it seemed too difficult to prove the causal link in the sulfur dioxide pollution cases, while the proposed highway, as an obvious "nuisance," was considerably easier to litigate. On a later occasion, described below, lawyers told Kojoshi victim leaders that a lawsuit was unjustified, since the government had already established the compensation system. The picture of victims' experiences with the legal system thus appears at first to be a classic example of "access denied," because of a legal profession reluctant to squander its scarce resources on a difficult case involving issues they considered to be already settled.

We also know that the victims' current involvement with lawyers and litigation came about through a combination of chance, determination, and public shaming. A victim leader was invited to a local bar association conference where she asked for help in organizing a lawsuit. Turned down, for the same reasons mentioned above, she took a group of 50 victims to a meeting of the Young Jurist's League (Seihokyo), a liberal-activist organiza- 
tion which included both judges and lawyers seeking to reform the legal system. This group, especially a subcommittee of lawyers involved in air pollution cases in other "designated zones" (including the infamous Minamata mercury poisoning cases), advised her to carry her story to a nationwide conference on human rights held by the Japan Federation of Bar Associations (Nichi-benren) in 1985. When she related her story of her groups' previous negative experience with lawyers, her audience squirmed with shame, especially those who were lawyers from the district that includes Kojoshi. Immediately after her speech, she was surrounded by chagrined lawyers offering free legal representation for members of her organization. The core of the present lawyers' group was formed on the spot. The strategy for the lawsuit was planned in a series of meetings that culminated in the December 1988 filing of the case.

\section{LITIGATION: OPPORTUNITY AND STRATEGY IN THE FACE OF SCARCITY}

Everyone we have interviewed agreed that, in the context of Japanese courts, a suit of this kind is likely to take 10 to 12 years before even a first judgment. The Kita-tonari case, like earlier cases in two other "designated zones," lasted at least that long.

From an American perspective, such delays appear extraordinary and suggest a major problem of access. Surely the time and money resources of the "haves" will advantage them in a battle between ordinary working class citizens and the government-backed industrial complex of Japan. Similar delays occur occasionally in some of the largest, most politicized cases in the United States. But a local case such as Kojoshi's, which has not received national attention, would be unlikely to face anything close to a 10-12-year delay, especially in view of the fact that most of the legal issues involved, and most of the factual questions, are almost identical to those involved in previously adjudicated cases.

The sources of delay in Japan are legion and can be summed up as a planned and well-executed government policy to restrict legal resources. For example, since class action suits are not accepted by Japanese courts, the Kojoshi action is defined as a large number of similar cases filed at the same time and handled by the same lawyers. Hence, when Kojoshi plaintiffs petitioned to have the usual filing fee $(0.5 \%$ to $1 \%$ of the amount of the suit) waived because of their inability to pay, the presiding judge decided it was necessary to review every one of the litigants' financial situations to rule on that preliminary motion for each plaintiff. The process took more than a year and a half. When that was done, the defendants appealed the decision on a subset of the cases and succeeded in having 
them added to the list of plaintiffs who would have to pay. ${ }^{19}$ The appeal, of course, added several more months to the suit.

Another source of delay is the frequent rotation of judges. Such cases are heard by a three-judge panel, and when any one of them is reassigned to another court, the new judge must spend time becoming acquainted with all the details of each of the 500 "cases." By 1992, one of the judges involved in the early Kojoshi case hearings had already been transferred elsewhere.

The most fundamental source of delay may be simply the strict control that the Japanese government, in cooperation with the major bar associations, maintains over entry into the legal profession. In 1988, government policy limited entry into the special training facility that serves as the gateway to becoming a judge, prosecutor, or private attorney to 500 per year..$^{20}$ The relatively small profession, on both sides of the bench, is not designed to grow with demand. Rather the stated aim is to preserve the highest quality of ethical service that can be achieved through tight regulation.

Delay is so taken for granted that the lawyers in the Kojoshi case knew they could wait until well after the start of the lawsuit (spring 1991, as it turns out) to begin interviewing their clients in detail about their symptoms. These interviews were needed to be sure that client descriptions of symptoms would conform with the technical terms of the compensation law in question. Such clarification was simply not needed prior to the filing of the case because the lawyers knew they would have plenty of time.

Most literature on law-centered dispute processing suggests that extended delay is likely to deter people from pursuing litigation and that delay is usually advantageous to only one of the two opposing sides.

It is surprising, therefore, to find that in this case, both sides appear to see delay as at least partly advantageous to them. Several of the defendant companies in the Kojoshi case are the same as those who "lost" in the Kita-tonari case. As a plaintiffs' lawyer points out, these defendants know perfectly well what the Kojoshi plaintiffs will be arguing in their own cases, because the arguments will be the same as those which brought partial victory for Kita-tonari plaintiffs. Yet the defendant lawyers in the Kojoshi case are engaged in exhaustive cross-examination of each Kojoshi plaintiff,

19. All litigants will eventually have to pay something. The issue here was only about which litigants had enough income to warrant demanding up-front payment rather than payment deducted from the amount they may "win" at the end of the case. Plaintiff's are charged a percentage based on the difference between their claim and the final judgment. Thus, if they "win" $70 \%$ of their original claim, they must pay $30 \%$ of the litigation fee. If they "win" only $20 \%$ of the claim, they pay $80 \%$ of the fee.

20. In 1992, professional organizations and the government agreed to increase this number from 500 to 700 . 
causing further delay, even though everyone in the courtroom knows not only what the questions will be but what the plaintiffs will answer. Hence delay appears to be useful to the defendants.

Yet delay also has come to figure in the plaintiffs' lawyers' strategies for maintaining commitment and a sense of progress among the victims. A new group of plaintiffs has been added to the original group of 500 . The purpose is only partly to compensate for the attrition of original plaintiffs and to increase pressure on the defendants. In addition, as the lawyers' team sees it, the action helps to recharge the determination and commitment of the original plaintiffs. It helps to "maintain a sense of momentum," in one lawyer's words. ${ }^{21}$

Evidently the risk of lost momentum, lost commitment, is a matter of concern among the plaintiffs' lawyers and movement leaders in this case as it has been in other cases. This difficulty is one major reason why a peculiar "deal" between plaintiffs and defendants' attorneys has become a standard feature of such suits. Plaintiffs and defendants have agreed that if a money judgment is made in favor of the plaintiffs, the defendants will immediately (in court before anyone leaves) sign and hand over checks in the proper amount to the plaintiffs' lawyers. These awards will be deposited by plaintiffs' lawyers and the principle will not be touched until after all appeals have been settled. Only the interest will actually be given to the plaintiffs themselves to tide them over until the "end" of the case.

Both sides have reasons to accede to this arrangement. Defendants prefer it because:

1. It protects the major portion of the award from being "squandered away" by plaintiffs of modest means who cannot repay such amounts if they should lose on appeal;

2. It protects the companies from the embarrassment of a typically well-publicized (often televised) visit to their headquarters by court officials demanding payment of the award. By immediately handing over the check in court, they minimize media sensationalism about their loss.

The plaintiffs' lawyers and organization leaders feel this arrangement benefits their movement. For one thing, by putting control over the award into the hands of the lawyers, the collective nature of the litigation is reaffirmed. In the Kita-tonari case, for example, 17 of the plaintiffs "lost" by being denied any monetary compensation. But because all the others

21. Our interpretation notwithstanding, our discovery that plaintiff leaders and lawyers consider delay advantageous may simply reflect the fact that only three years had passed since filing of the litigation when we completed data collection in 1992. Delay could become seriously disadvantageous if several more years pass before some kind of conclusion, a point we intend to monitor in future research. 
"won" and their winnings were pooled by this arrangement, the 17 losers could be included in the overall dispersal of funds from the interest generated by the collected awards. The "deal" thereby defeats the individualizing effects of the legal system's procedures and juridical definitions.

Second, prior experience has taught movement leaders that individual plaintiffs tend to drift away from the movement as soon as they receive awards in their lawsuits. By pooling the awards and dispersing the interest on a collective basis, the group's leaders can forestall this disintegrative tendency. This social movement logic also leads to the view that delay, in itself, is not necessarily bad, so long as a sense of momentum can be maintained. Once engaged, litigation carries with it the threat that any truly final outcome, whether victory or defeat, will pull the rug out from under the movement.

In discussing this last bit of strategy with both plaintiffs' leaders and their attorneys, we discovered potentially divisive differences between them concerning both short- and long-range objectives. The discovery of differences between lawyers and their clients is, in itself, not particularly surprising. Previous studies have shown a variety of ways in which lawyer/ client interests diverge. ${ }^{22}$ Lawyers, for example, are depicted as agents of compromise, bringing their clients into line with "the facts" of law, litigation, and what is realistic. Business clients resist the "legalizing" initiatives of their own lawyers. Lawyer language mystifies the average client. Therefore it should not be surprising to find lawyer/client disagreement in Japan. However, the situation here is different enough from already published reports to warrant special attention, especially since it appears to bear on our understanding of the "natural history" of this social movement.

In our research, there is a longer-term dynamic between litigants and their lawyers that suggests the flow of influence in both directions. For one thing, the "interests" 23 of plaintiffs in this kind of case vary greatly from one plaintiff to another. These differences must somehow be reconciled if the litigation project is to proceed. We have found that four different

22. See, e.g., Austin Sarat \& William L. F. Felstiner, "Law and Strategy in the Divorce Lawyer's Office," 20 Law $\mathcal{E}$ Soc'y Rev. 93 (1986); Stewart Macaulay, "Lawyers and Consumer Protection Law," 14 Law \& Soc'y Rev. 161 (1979); Lenore Weitzman, The Divorce Revolution: The Unexpected Social and Economic Consequences for Women and Children in America (New York: Free Press, 1985); William M. O'Barr \& John M. Conley, "Lay Expectations of the Civil Justice System," 22 Law \& Soc'y Rev. 137 (1988).

23. Wilhelm Aubert, "Law as a Way of Resolving Conflicts: The Case of the Small Industrialized Society" in Laura Nader, ed., Law in Culture and Society (Chicago: Aldine, 1969). Here Aubert proposed distinguishing between conflicts of interest and conflicts of value. Dispute transformation literature has presented this dichotomy as a dimension along which lawyers try to move conflicts from the more intractable value side toward the resolvable side of interests. As the following discussion demonstrates, actions in the Kojoshi case do not neatly support either the distinction between conflicts of interest and of value or the view of lawyers as agents deemphasizing values. 
kinds of concerns and interests motivate plaintiffs in the Kojoshi case and that these create different and potentially conflicting sources of reaction to what the lawyers are doing. First are what we call Money Crusaders (MCs). These plaintiffs seek nothing more than a quick and lucrative settlement and have marginal involvement in the movement. One such plaintiff readily admitted that he joined the victims' organization just so he could litigate. He had had no previous interest in the movement but assumed that membership in the larger organization was a prerequisite for membership in the litigants' group. ${ }^{24}$ For Money Crusaders, the machinations of lawyers making arrangements that exploit delay to invigorate the movement would be seen as irrelevant or counterproductive if they knew of them. But their involvement is so marginal that they simply bide their time and "fill in the forms" in order to keep their place in the legal proceedings. MCs are also the most vulnerable to litigant attrition. Their desire for compensation can be subverted by threats made by defendant companies against their jobs, or against, for example, prospective spouses who can be scared away from marriage by threats to their economic well-being.

We call the second type of litigant the Local Crusader (LC). LCs see the monetary outcome as significant only for its symbolic value. They seek justice. They want a "final reckoning" with the specific adversaries they have taken to court. Victory in court is only one of the ways they seek to achieve this. They will also join in demonstrations at company offices and participate in "for television only" actions that they see as building pressure on defendants to "do the right thing." For this group, the largerframe strategies for sustaining the social movement are potentially at variance with their own pursuit of closure, of final justice. Yet their more ideological involvement means that their aims must be accommodated in the litigation plans so that their participation will continue.

A third, much smaller group we call National Crusaders (NCs). Ideologically similar to Lcs, but with a broader and longer range vision, NCs treat the lawsuit as part of a process of engaging ordinary people in actions which create, maintain, and, if possible, increase pressure on Japan's business/government combine (what they see as a kind of Japanese "power elite"). For them, litigation is part of an arsenal of actions that pressure decision makers to rethink plans for development, expansion, economic growth, and the negative environmental (and social) consequences.

Finally, among victim group leaders, whom we classify as World Crusaders (WCs), there is a broader agenda yet-that of mobilizing a global environmental awareness and movement that will protect the environment

24. A litigants' group leader and a lawyer assured him (to his surprise) during the interview that all victims, whether members of the larger association or not, had been welcome to join the litigants' group as a litigant. His previous nonmembership in the umbrella victims' group is simply an indication of his specific motives for involvement in the lawsuit. 
in general, not just in Japan. One Kojoshi leader recently spoke at an environmental conference in Thailand because the national organization to which she belongs has become concerned about the impact of Japanese foreign aid and development projects on the environment in Southeast Asia. Other members of the national federation were delegates to the June 1992 alternative Earth Summit staged in conjunction with the United $\mathrm{Na}$ tions environmental conference in Brazil.

For NCs and WCs, the tension with their lawyers comes from a different kind of concern. Since they see the objective as lying beyond the limits of their town and their lawsuit, they find the lawyers too focused on winning their case rather than using it for the broader campaign. For them, the delays in court are an opportunity to educate the lawyers on the case, increase their general sensitivity to environmental issues, and expand the overall involvement of the profession in the movement. They are aware of the existence of the National Committee of Pollution Opposition Counsels, which cooperates with the national victims' federation, and they seek to draw their own district's lawyers into expanded participation in it. Hence, what might have been a crisis in the case, a disabling illness to the head of the lawyers' team, is actually, to victims' group leaders, an opportunity. The illness forced the redistribution of the head lawyer's work among four other lawyers, and plaintiff group leaders view this as broadening the involvement of the legal profession in the case. "Now it is no longer all in the head of one lawyer." Kojoshi victims' group leaders hope to use their upcoming 10 years of litigation to raise their lawyers' consciousness to the level they observed among lawyers in the Kita-tonari case. They attribute the "better awareness" of Kita-tonari lawyers to their prolonged contact with Kita-tonari victims during their litigation.

For NCs and WCs, as for the lawyers, delay has value because it prolongs the involvement of MCs and LCs who are perceived as likely to "drop out" once a judgment is rendered, unless the judgment can be converted into further grounds for action.

There is irony in the beliefs of NCs and WCs that their lawyers need motivating and educating. Several of these lawyers see themselves as part of a long-term movement to pressure government on a wide variety of "human rights" issues including environmental pollution. They see the preservation of litigant interest, commitment, and involvement as both vital and problematic. It is true that they seek a good judgment for their specific clients and achieving this demands many tedious hours of attention to detail. It is also true that they regard the delays in court as a potential threat to continued client involvement. ${ }^{25}$ However, they are now, and

25. Lawyers and movement leaders estimate that during the first three years of litigation about $10 \%$ of the plaintiffs had become "inactive." These are victims who have unofficially dropped out of the case, although their names remain on the roles as plaintiffs. 
have been for years, in close professional contact with a nationwide network of lawyers working on cases involving pollution victims. Moreover, several of them have been involved in similar litigation for at least the past 20 years. That is, their involvement in this kind of work dates back to that point in Japan's postwar history when the "Big Four" pollution cases were focusing the nation's attention on pollution specifically and the dangers of unrestrained economic development more generally. Further, among their role models for this kind of work are lawyers whose first clients were opponents of Japan's prewar military government, and who later went on to lead the litigation in the "Big Four" pollution cases. An unbroken chain of pollution cases has kept the basic issue before the courts almost continuously since the 1960s, and one objective of lawyers involved in the Kojoshi case is to "keep up the pressure" on government and industry to move away from total commitment to economic development toward a greater concern for other issues such as the environment.

From the perspective of lawyers with this longer-range view, there is a persistent need to support and direct the Kojoshi movement and others like it from above. Yet as we have already seen, a significant subset of plaintiff leaders view the lawyers as too narrow in their thinking and commitment. From both sides, however, we sense that the "poverty of resources" within the Japanese legal system comes to serve as a potentially valuable tool in long-range strategies of change.

Significantly for our comparison with the United States, all the lawyers involved in the Kojoshi case, and lawyers we have interviewed who were involved in some of the "Big Four" cases, say that they are not concerned about setting legal precedents with their litigation. American lawyers would describe their actions as designed either to take advantage of precedents set in previous cases or to obtain judicial rulings that will set new precedents favorable to their nationwide movement. Such rule making is not an important goal in such cases in Japan.

While this is a significant verbal and conceptual difference between Japanese and American lawyers, in practice it may be less significant, since the overall Japanese oppositional strategy of maintaining a steady stream of similar lawsuits appears to be designed to maintain an unavoidable presence in the political and governmental arena so that those forces interested in cutting back on environmental protection and victim compensation will not be able to act without restraint.

Lawyers explain this phenomenon as a response to "pressure" put on plaintiffs by family members and/or employers. Family members, for example, may find their search for a job or a spouse being blocked because of their relative's involvement in litigation. 


\section{CONCLUSION}

Kojoshi is not unique in the pattern its antipollution citizens' movement has followed. Even its use of litigation follows a model that we can see in several previous cases. The persistence and repetition of this pattern comes from the existence of an oppositional network involving professionals (including lawyers, doctors, and teachers) and a smaller number of grass-roots leaders who are based in local groupings of the discontented, such as the movement in Kojoshi. Litigation has, for those in the network, become part of a strategy for organizing and expressing opposition to the dominant political and economic tendencies of the postwar years. As such, this type of litigation should be viewed as a form of political action whose relevant outcomes are only partially determined by legal doctrine, the structure of legal institutions, or the attitudes of judicial officers. Litigation provides a means of assembling actors with disparate motives (all the way from Money Crusaders to World Crusaders) into a force that places and maintains environmental activism in the public arena. The apparent inadequacies of the Japanese legal system, its slow and inefficient courts, its highly restricted legal profession, become part of the context that leaders of social movements live with and use. Perhaps they would not object to a swift, inexpensive court system that would rule sternly and regularly in their favor. But leaders such as those in Kojoshi view litigation as useful even without such a legal environment.

Are the lawyers and movement leaders involved in a conflict of interest here against the ordinary members of the plaintiffs' group? From their point of view, the answer is no. They see this group-based litigation as the only effective way, given the severe resource restrictions of the Japanese legal system, for any individual air pollution victim to exercise legal environmental rights. In other words, an individual victim's only hope is to contribute to the sustenance of the movement, and their specific role is that of litigant. Therefore the lawyers' ability to exploit the reality of delay is justified by its broader significance for all air pollution victims.

Hence, even though Japan has a tiny fraction of the number of lawyers and courts available to activists in the United States, the Japanese legal profession and legal institutions have become a partial but regular contributor to the development of environmental protection consciousness and action in Japan.

Returning to the issue of culture-based theories we discussed at the outset, we view the pattern of Kojoshi-style action as evidence that cultural difference, in this case Japan's predominance of particular conflict-avoidance attitudes, provides a weak platform for understanding what we see. Culture theorists ${ }^{26}$ have tried to explain law-related phenomena in Japan

26. Kawashima, "Dispute Resolution" (cited in note 5). 
as an expression of the pervasive emphasis on $W a$, the value of harmony. From such a perspective people avoid overt conflict to conform with the value. The Kojoshi experience demonstrates quite clearly that noninvolvement in litigation was primarily a function of the severe difficulties potential litigants faced in engaging the legal system on their side.

Viewing Japan through the culture lens has led some more recent analysts $^{27}$ to propose a dichotomy between behaviors that successfully promote the goal of harmony and behaviors that result in a kind of chaotic, uncontrollable slide into "intensified conflict" 28 or conflict that is uniquely "difficult to contain." 29 Their view is that societies which fail to develop a rich ecology of dispute-handling alternatives, including rightsbased legal institutions, are "fragile," vulnerable to protracted, uncontainable conflicts when conditions prevent the preservation of harmony.

The Kojoshi litigation, and the pattern of other cases of which it is a part, are neither an expression of Wa nor an example of conflict "difficult to contain." The conflict is protracted and the behavior may appear at first glance to be "unJapanese." However, we have shown that the actions taken in Kojoshi are systematic, carefully and methodically planned, and quite clearly defined in terms of objectives and strategies. These kinds of lawsuits are part of an ongoing, overt pattern of conflict that expresses class-based divisions in Japanese society. By focusing on Wa, culture-based explanations divert attention from what may be much more important differences between the social, economic, and political structures of Japan and the United States, especially those concerning connections between social class, political power, and the structure of legal institutions.

27. T. S. Lebra, "Nonconfrontational Strategies for Management of Interpersonal Conflicts," in E. S. Krauss, T. P. Rohlen, \& P. G. Steinhoff, eds., Conflict in Japan 41-60 (Honolulu: University of Hawaii Press, 1984) ("Lebra, 'Nonconfrontational Strategies" "); Hamilton \& Sanders, Everyday Justice (cited in note 7).

28. Lebra, "Nonconfrontational Strategies," at 56.

29. Hamilton \& Sanders, Everyday Justice 214. 


\section{APPENDIX THE KOJOSHI LITIGANTS' LEGAL CASE}

\section{The Legal Issues}

Article 719, Section 1 of the Japanese Civil Code provides that those who caused damages to others through joint torts (kyodo fuho Koi) are liable for compensation. Like all other suits on air pollution, the Kojoshi litigation is based on this provision. The plaintiffs have to prove two crucial elements: (1) the causation between air pollution and their diseases; (2) whether the defendants' actions form joint torts.

On the issue of causation, previous decisions in pollution cases have developed various methods to judge it. They commonly have two elements: the general causal relationship and the specific causal relationship. First the plaintiffs must prove an epidemiological, general relationship between air pollution and diseases in the given area. Second, the plaintiffs must prove, for each plaintiff, the specific relationship between air pollution and diseases of the given plaintiff. This second element is often a main point of the defense. However, these two elements appear to be related in court decisions. When the evidence about the first element is strong, courts appear to lower the level of proof on the second element. Probably because of this pattern, the complaint filed by the Kojoshi plaintiffs includes claims about the first element, while it says almost nothing about the second element. (Plaintiff's lawyers in the Kojoshi case started their investigation about specific diseases of the plaintiffs three years after the start of the litigation.)

On the issue of joint torts, subjective elements such as conspiracy or shared perceptions are not required for the defendants' actions to form joint torts. Even when such subjective elements are lacking, the defendants' actions may be held to form joint torts, while levels of contribution may vary. For instance, if a company continues to operate its factories while knowing that the level of air pollution in the given area is reaching a dangerous level and that its factories are a small part of the pollution sources, the company may be held liable for joint torts in a weak sense. The company may argue for a reduction of its responsibility compared to larger pollution sources. If, on the other hand, a group of companies in the area operates with close financial and personnel relationships and if they are all pollution sources, they may be held liable for joint torts in a strong sense. Each of them may be held liable for the entire damages. The plaintiffs' complaint argues that the defendants should be held liable in this stronger sense, for they have continued their operation while clearly knowing the situation for many years. If the defendants' actions are held to form joint torts, the plaintiffs will have no need to prove specific liability of each defendant. The defense, of course, argues that the defendants' actions do not form joint torts even in a weaker sense.

Arguing that there is a causal relationship between air pollution and their diseases and that the defendants are liable for joint torts, the plaintiffs seek (1) injunction and (2) monetary awards. In their claim for injunction, the plaintiffs argue that while there are other sources of pollution, the defendants are the largest contributors and the level of pollution will be much improved by controlling their emissions. In the claim for monetary awards, there is an element that is unique to the Kojoshi litigation.

Compensation for damages generally includes two elements: (1) compensation of lost interests (isshitsu rieki) and other monetary damages and (2) compensation of psychological damages (isharyo). While the plaintiffs of other cases sought both, the Kojoshi plaintiffs sought only the latter plus lawyers' fees. Thus, the amounts sought by the Kojoshi plaintiffs are lower than those in other cases, only up to 30 million yen, compared to 50 million yen in the Kita-tonari litigation. This self-imposed limitation reflects prior court decisions that deducted the money the plaintiff received under the Pollution Victim Compensation Law from the monetary award the plaintiff might have received by the court decision. Therefore, it was quite possible that the plaintiff might receive nothing from the court decision because he had previously received too much 
under the Compensation Law. However, scholars argue that the amount of compensation under the Compensation Law is set at $80 \%$ of the income, so that it does not include compensation of psychological damages. Probably because of this consideration, the Kojoshi plaintiffs sought only isharyo compensation, which is arguably immune from deduction. While their amounts may look too small to American eyes, they reflect prevailing judicial decisions in Japan.

Looking at it this way, we may say that the Kojoshi and similar cases in Japan also seek to establish new precedents, albeit in an extremely piecemeal way. Easing the requirements on causation or joint torts will be an improvement for plaintiffs. Persuading the court on the need and enforceability of injunction as a legal remedy will be a tremendous victory. Even the holding that compensations under the Compensation Law do not include isharjo will be progress. In a country where the judiciary is extremely positivistic (in the sense of legal positivism), a small doctrinal increment is often the most that plaintiffs can expect to achieve.

\section{Issues and Awards in the Kita-tonari Case}

While the Kojoshi plaintiffs limited their claims to isharyo, the Kita-tonari plaintiffs sought the so-called comprehensive claim (hokatsu seikyu) plus lawyers' fees, without specifying monetary and psychological damages. Their claims varied between 20 million yen (for a living minor) and 50 million yen (for deceased).

The court first held that there were two main causal mechanisms of air pollution in the area, one caused by sources located in the southwestern part of the area, the other caused by sources in the northeastern part. The 10 defendant companies were all located in the southwestern part and, thus, are liable for only half of the damages before 1969. Then the court held that since there were other sources of pollution, the defendant companies contributed to less than $35 \%$ of pollution in 1970 and less than $20 \%$ in 1973. Each defendant's liability to each plaintiff was to be calculated according to this scheme. Furthermore, the court took into consideration the compensation each plaintiff had already received under the Compensation Law and under a neighboring major city's ordinance and deducted part of such compensation from the total amount of award each plaintiff should receive. Thus, the court held that seven plaintiffs had already been fully compensated.

As defendants, the government and the highway corporation were held not liable in the court's decision. The key to this decision was the problem of proving causation. The court held that while the causal relationship between sulfur dioxide (from factories and power plants) and the diseases was proven, there was no proof of the causal relationship between nitrogen dioxide (from highway traffic) and disease. Thus only the 10 companies were left as liable defendants.

The court held, moreover, that the defendant companies were liable for only part of the damages and that part of this limited liability had already been covered by other compensation schemes. The net result was 357 million yen (about $\$ 3.36$ million), which was only about 3 million yen $(\$ 28,000)$ for each plaintiff.

The basic problem behind all this is the way in which Japanese courts estimate the value of human life. We should note that the maximum compensation sought for deceased victims was only 50 million yen. This reflects the going rate in court decisions. Moreover, since the defendant companies are only part of the cause, they compensate only part of the entire amount. Therefore, monetary compensation is only a small part of the plaintiff team's calculation of success or failure of the litigation. More important is the achievement of a finding that there are uncompensated pollution victims and the development of legal doctrines that would make this type of litigation slightly more winnable. 
